\title{
Ursodeoxycholic acid prevents cytochrome $c$ release in apoptosis by inhibiting mitochondrial membrane depolarization and channel formation
}

\author{
Cecilia MP Rodrigues ${ }^{1,3}$, Xiaoming $\mathrm{Ma}^{1}$, \\ Cheryle Linehan-Stieers ${ }^{1}$, Guangsheng Fan ${ }^{1}$, \\ Betsy T Kren ${ }^{1}$ and Clifford J Steer ${ }^{\star, 1,2}$ \\ ${ }^{1}$ Department of Medicine, University of Minnesota Medical School, \\ Minneapolis, Minnesota 55455, USA \\ 2 Department of Cell Biology, University of Minnesota Medical School, \\ Minneapolis, Minnesota 55455, USA \\ ${ }^{3}$ Instituto Superior de Ciências da Saúde - Sul, Monte de Caparica, Portugal \\ * corresponding author: CJ Steer, Department of Medicine, Box 36 UMHC, \\ University of Minnesota Medical School, 420 Delaware Street S.E., \\ Minneapolis, MN 55455, USA. tel: 612-624-6648; fax: 612-625-5620; \\ e-mail: steer001@maroon.tc.umn.edu
}

Received 19.4.99; revised 3.6.99; accepted 6.7.99

Edited by R.A. Lockshin

\section{Abstract}

The hydrophilic bile salt ursodeoxycholic acid (UDCA) is a potent inhibitor of apoptosis. In this paper, we further characterize the mechanism by which UDCA inhibits apoptosis induced by deoxycholic acid, okadaic acid and transforming growth factor $\beta 1$ in primary rat hepatocytes. Our data indicate that coincubation of cells with UDCA and each of the apoptosis-inducing agents was associated with an approximately $80 \%$ inhibition of nuclear fragmentation $(P<0.001)$. Moreover, UDCA prevented mitochondrial release of cytochrome $c$ into the cytoplasm by $70-75 \%$ $(P<0.001)$, thereby, inhibiting subsequent activation of DEVD-specific caspases and cleavage of poly(ADP-ribose) polymerase. Each of the apoptosis-inducing agents decreased mitochondrial transmembrane potential and increased mitochondrial-associated Bax protein levels. Coincubation with UDCA was associated with significant inhibition of these mitochondrial membrane alterations. The results suggest that the mechanism by which UDCA inhibits apoptosis involves an interplay of events in which both depolarization and channel-forming activity of the mitochondrial membrane are inhibited.

Keywords: Bax; bile acid; cytochrome $c$; permeability transition; mitochondria

Abbreviations: DCA, deoxycholic acid; DEVD, Asp-Glu-Val-Asp; $\mathrm{DiOC}_{6}(3), 3,3$-dihexyloxacarbocyanine; MPT, mitochondrial permeability transition; $\Delta \psi_{\mathrm{m}}$, mitochondrial transmembrane potential; OA, okadaic acid; PARP, poly(ADP-ribose) polymerase; pNA, $p$ nitroanilide; SDS-PAGE, sodium dodecyl sulfate polyacrylamide gel electrophoresis; TGF- $\beta$, transforming growth factor beta; UDCA, ursodeoxycholic acid

\section{Introduction}

Oral administration of ursodeoxycholic acid (UDCA) has been shown to substantially improve clinical and biochemical indices in a wide variety of liver diseases. ${ }^{1-5}$ Despite its clinical efficacy, the precise mechanism by which UDCA improves liver function during cholestasis is not entirely understood. ${ }^{6}$ It is generally accepted that hydrophobic bile acids play a key role in liver injury during cholestasis and can induce hepatocyte apoptosis both in vitro ${ }^{7-9}$ and in vivo. ${ }^{10}$ It has been proposed that the observed cytoprotective effect of UDCA results from mechanisms beyond simply displacing toxic bile acids from the liver. For example, UDCA significantly inhibited the mitochondrial permeability transition (MPT) induced by hydrophobic bile acids in isolated mitochondria. ${ }^{11}$ Interestingly, liver mitochondria from bile duct-ligated rats demonstrated resistance to bile acid-induced MPT, suggesting an adaptive phenomenon to the toxicity of cholestasis. ${ }^{12}$ Finally, we have recently shown that UDCA plays a unique role in modulating the apoptotic threshold in both hepatic and nonhepatic cells. The effect was observed for a variety of agents acting through different apoptotic pathways involving mitochondrial membrane perturbation. ${ }^{10,13}$

It is widely recognized that alterations in mitochondrial function, and particularly the MPT, play a key role during apoptosis in many cell types. In fact, the loss of mitochondrial transmembrane potential $\left(\Delta \psi_{\mathrm{m}}\right)$, release of caspase activators and participation of pro- and antiapoptotic $\mathrm{Bcl}-2$ family proteins appear to be critical events during apoptosis. The central role of mitochondria in apoptosis was initially suggested in cell-free systems using Xenopus egg extracts in which nuclear condensation and DNA fragmentation were dependent on the presence of mitochondria. ${ }^{14}$ In subsequent studies, untreated HeLa cell extracts induced the activation of caspase-3 and DNA fragmentation after addition of deoxyadenosine triphosphate and cytochrome $c$, which was identified as the mitochondrial factor. ${ }^{15}$ In whole cells, cytochrome $c$ redistributes from the mitochondria to the cytosol during apoptosis and this process can be inhibited by the antiapoptotic proteins $\mathrm{Bcl}-2$ or $\mathrm{Bcl}-\mathrm{X}_{\mathrm{L}}{ }^{16-18}$ Depending on the cell type, cytochrome $c$ release can result in cell death by either an apoptotic pathway involving Apaf-1-mediated caspase activation or necrosis associated with collapse of electron transport. In fact, inhibition of cytochrome $c$ activity with blocking antibodies has been shown to inhibit apoptosis. $^{19}$ 
The molecular mechanisms for release of caspaseactivating proteins from mitochondria into the cytosol are beginning to unfold. It has been proposed that opening of the MPT pore leads to a collapse of the mitochondrial inner transmembrane potential, expansion of the matrix space, and subsequent rupture of the outer membrane..$^{20-25}$ Inhibition of MPT pore opening prevents cell death in some systems, supporting a central role for MPT in apoptosis. $^{26}$ Furthermore, while Bcl-2 blocks cell death and disruption of $\Delta \psi_{\mathrm{m}},{ }^{21,25-29}$ the pro-apoptotic family member Bax induces both apoptosis and MPT. ${ }^{30,31}$ In fact, Bax interacts directly with MPT pores in isolated mitochondria to induce the permeability transition and cytochrome $c$ release $^{32}$ Bax also interacts with the constitutive mitochondrial inner membrane protein, adenine nucleotide translocator, thus increasing membrane permeability and inducing cell death. ${ }^{33}$ Interestingly, other studies indicate that cytochrome $c$ release and caspase activation can occur prior to, and independently of, any detectable mitochondrial membrane depolarization, implying that opening of the MPT pores is a downstream event to caspase activation. ${ }^{34,35}$ Moreover, caspases themselves can induce MPT pore opening, which in turn activates additional caspases, thereby creating self-amplifying feedback loops. ${ }^{36,37}$

A number of recent observations suggest a growing complexity in the molecular regulation of apoptosis. For example, the efflux of cytochrome $c$ from mitochondria may also occur through a mechanism independent of MPT pore opening. In support of this, disruption of the outer membrane occurs only in a subpopulation of mitochondria, despite the release of cytochrome $c$ from a larger pool of mitochondria. In addition, it has been shown that Bax overexpression triggers the release of cytochrome $c$ in different cell types independently of MPT. ${ }^{38,39}$ Finally, Bcl2 , a potent anti-apoptotic protein, has been shown to prevent programmed cell death via a caspase-independent mechanism. ${ }^{40}$
This study was done to examine the mechanism of UDCA in regulating mitochondrial membrane perturbation during apoptosis induced by deoxycholic acid (DCA), okadaic acid and transforming growth factor $\beta 1$ (TGF- $\beta 1$ ) in isolated rat hepatocytes. Our results demonstrate that each of these agents can trigger mitochondria to release cytochrome $c$, which in turn induces cytosolic caspase-3 activation, and cleavage of the nuclear enzyme poly(ADPribose) polymerase (PARP). These apoptotic events are significantly inhibited by UDCA, which partially prevents depolarization of the mitochondrial membrane as well as translocation of Bax from the cytosol to the mitochondria. Thus, UDCA inhibits apoptosis induced by a variety of unrelated agents by both preventing disruption of mitochondrial membranes and altering their channelforming activity.

\section{Results}

\section{UDCA inhibits apoptosis induced by DCA, okadaic acid, and TGF- $\beta 1$ in primary rat hepatocytes}

Significant levels of apoptosis occurred in cultured primary rat hepatocytes after incubation with DCA, okadaic acid or TGF- $\beta 1$. Apoptosis was assessed by changes in nuclear morphology with Hoechst staining and was characterized by condensation of chromatin and nuclear fragmentation with formation of apoptotic bodies. Incubation of cells with $50 \mu \mathrm{M}$ DCA resulted in a significant increase in the number of apoptotic cells which continued to increase through $6 \mathrm{~h}$ (Figure 1A). ${ }^{10}$ The hepatocytes displayed a maximum apoptotic response to okadaic acid and TGF- $\beta 1$ at 24 and $30 \mathrm{~h}$, respectively (Figure $1 \mathrm{~B}, \mathrm{C}$ ). Incubation with UDCA alone produced no significant changes in nuclear morphology compared to controls. In addition, UDCA protected against apoptosis induced by DCA, okadaic acid and
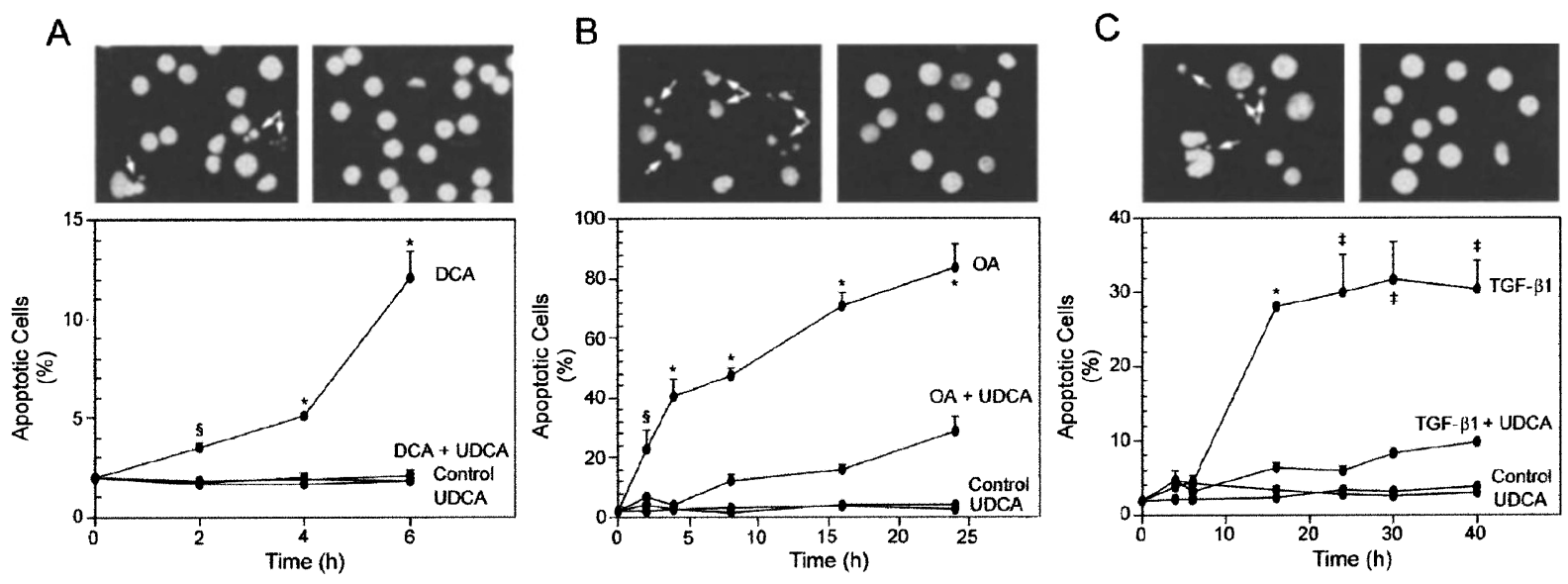

Figure 1 UDCA inhibits DCA-, okadaic acid-, and TGF- $\beta 1$-induced apoptosis in primary rat hepatocytes. Cells were incubated with either $50 \mu \mathrm{M}$ DCA (A), $25 \mathrm{nM}$ okadaic acid (OA) (B), $1 \mathrm{nM}$ TGF- $\beta 1$ (C), $100 \mu \mathrm{M}$ UDCA, a combination of inducer plus UDCA, or no addition (control) as described in Materials and Methods. Apoptotic cells were identified by morphological changes characterized by condensed chromatin, fragmentation, and apoptotic bodies. Fluorescence microscopy of Hoechst staining (top) after incubation of rat hepatocytes with (A left) DCA and (right) DCA+UDCA for $6 \mathrm{~h}$; (B left) OA and (right) OA+UDCA for 16 h; or (C left) TGF$\beta 1$ and (right) TGF- $\beta 1+$ UDCA for $24 \mathrm{~h}$. Percentage of apoptosis (bottom) in cells after treatment with inducer, UDCA, the combination, or no addition for the indicated time points. The results are means \pm S.E.M. for at least three different experiments. $\S P<0.05 ; \ddagger P<0.01 ;{ }^{*} P<0.001$ from all others at the same time points 
TGF- $\beta 1$ by approximately $80 \%$ at 6,16 and $24 \mathrm{~h}$, respectively. Similar changes were also observed when cell viability was assessed by trypan blue exclusion. Moreover, coincubation of hepatocytes with the tauroand glyco-conjugated derivatives of UDCA gave similar results for inhibition of apoptosis induced by all three agents. In contrast, at similar concentrations neither of the hydrophilic bile acids, hyodeoxycholic nor taurocholic acid inhibited apoptosis (data not shown).

\section{UDCA inhibits DCA-induced release of cytochrome $c$ after MPT in isolated mitochondria}

Mitochondria were isolated from rat liver to characterize the temporal association of MPT induction with the release of cytochrome $c$, as well as morphologic changes. Neither okadaic acid nor TGF- $\beta 1$ at the highest concentrations induced mitochondrial swelling, as determined both spectrophotometrically and by electron microscopy (Figure 2). In contrast, the MPT induced by DCA was associated with mitochondrial swelling, loss of cristae, and ultimately rupture of the outer membrane, resulting in a markedly reduced number of intact mitochondria. Pretreatment of the isolated mitochondria with UDCA inhibited the DCA-induced MPT by $42.5 \pm 4.6 \% \quad(P<0.001)$, and significantly increased the number of intact mitochondria. Similarly, cyclosporine $A$, an inhibitor of the megapore channel, reduced DCAinduced mitochondrial swelling by $48.7 \pm 4.4 \% \quad(P<0.001)$ and increased morphologic integrity. Incubation with phenylarsine oxide, a potent inducer of MPT, also resulted in a significant increase in mitochondrial swelling which was inhibited $43.2 \pm 4.1 \%(P<0.001)$ with UDCA. Neither UDCA, its tauro- and glyco-conjugated derivatives nor cyclosporine A alone altered the MPT or the gross morphology of the mitochondria. Pretreatment with the conjugated derivates of UDCA also inhibited DCA-induced mitochondrial swelling by $40.8 \pm 1.1$ and $42.0 \pm 1.6 \%$, respectively. No significant morphologic changes were observed with either hyodeoxycholic or taurocholic acid, and they did not inhibit DCA-induced MPT and membrane disruption.

We next investigated whether the efflux of cytochrome $c$ from the intramembranous space of mitochondria could be explained by an increase in MPT. Cytochrome $c$ protein levels were determined by Western blot analysis of the mitochondrial pellets and supernatants following the MPT assay. Control mitochondria exhibited no detectable release of cytochrome $c$ (Figure 3 ). In contrast, cytochrome $c$ accumulated in the supernatant after incubation with DCA, while mitochondrial-associated levels were similarly reduced. Neither incubation with okadaic acid nor TGF- $\beta 1$ induced cytochrome $c$ efflux (data not shown). Addition of either UDCA or cyclosporine $A$ decreased DCA-induced release of cytochrome $c$ by $>70 \% \quad(P<0.001)$. UDCA also significantly reduced $(55.9 \pm 7.6 \%, \quad P<0.001)$ the cytochrome $c$ release associated with phenylarsine oxide induction of MPT. Moreover, the tauro- and glyco-conjugated derivatives of UDCA also inhibited mitochondrial efflux of cytochrome $c$ by at least $80 \% \quad(P<0.001)$. In contrast, neither hyodeoxycholic acid nor taurocholic acid inhibited DCAinduced cytochrome $c$ release.

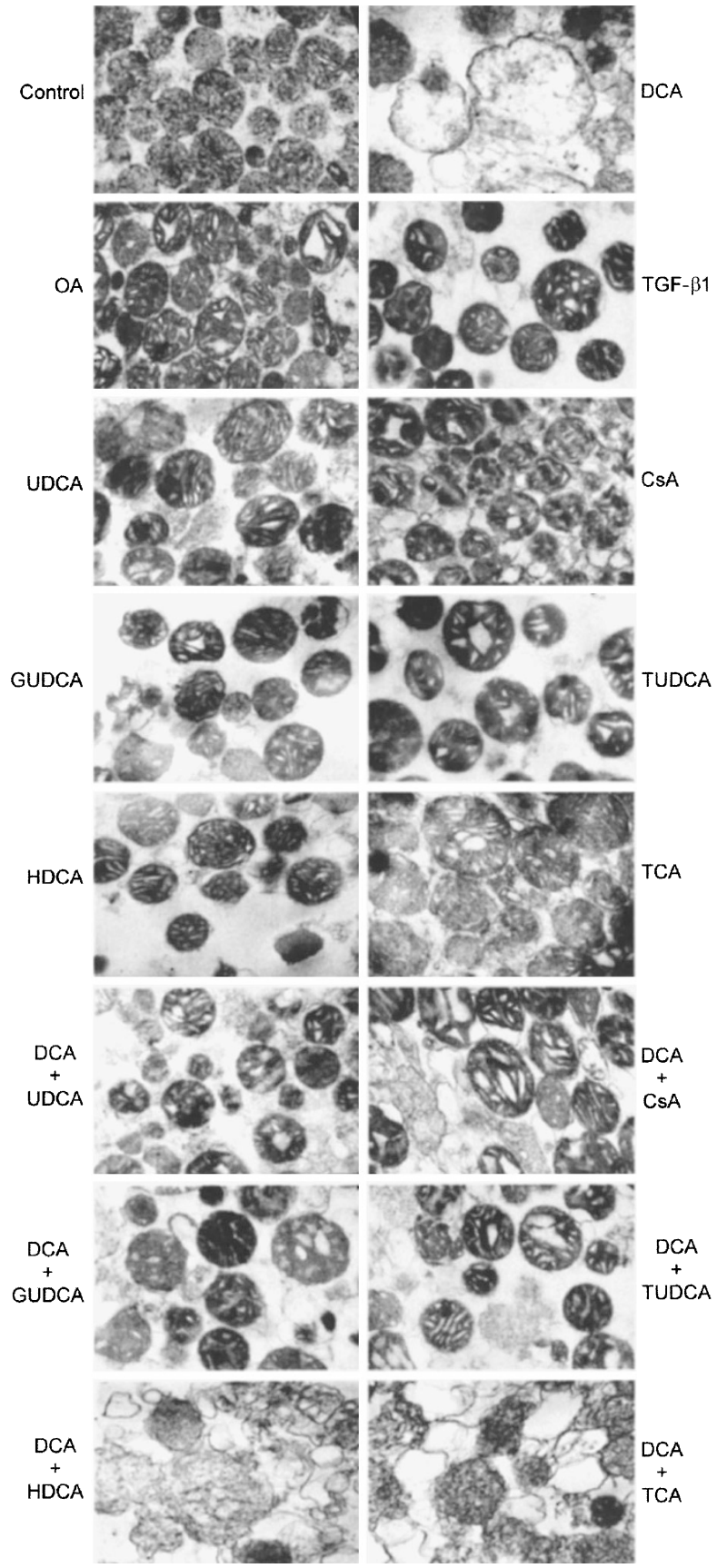

Figure 2 UDCA inhibits DCA-induced morphologic changes associated with MPT in isolated mitochondria. Electron microscopy of mitochondria after isolation and incubation $(1 \mathrm{mg} / \mathrm{ml})$ with either no addition (control), $250 \mu \mathrm{M}$ DCA, $125 \mathrm{nM}$ okadaic acid (OA), $5 \mathrm{nM}$ TGF- $\beta 1,500 \mu \mathrm{M}$ UDCA, $5 \mu \mathrm{M}$ cyclosporine A (CsA), $500 \mu \mathrm{M}$ glycoursodeoxycholic acid (GUDCA), $500 \mu \mathrm{M}$ tauroursodeoxycholic acid (TUDCA), $500 \mu \mathrm{M}$ hyodeoxycholic acid (HDCA), $500 \mu \mathrm{M}$ taurocholic acid (TCA), DCA+UDCA, DCA+CsA, DCA+GUDCA, DCA+TUDCA, DCA+HDCA, or DCA+TCA, in respiration buffer as described in Materials and Methods. Magnification $\times 25000$ 


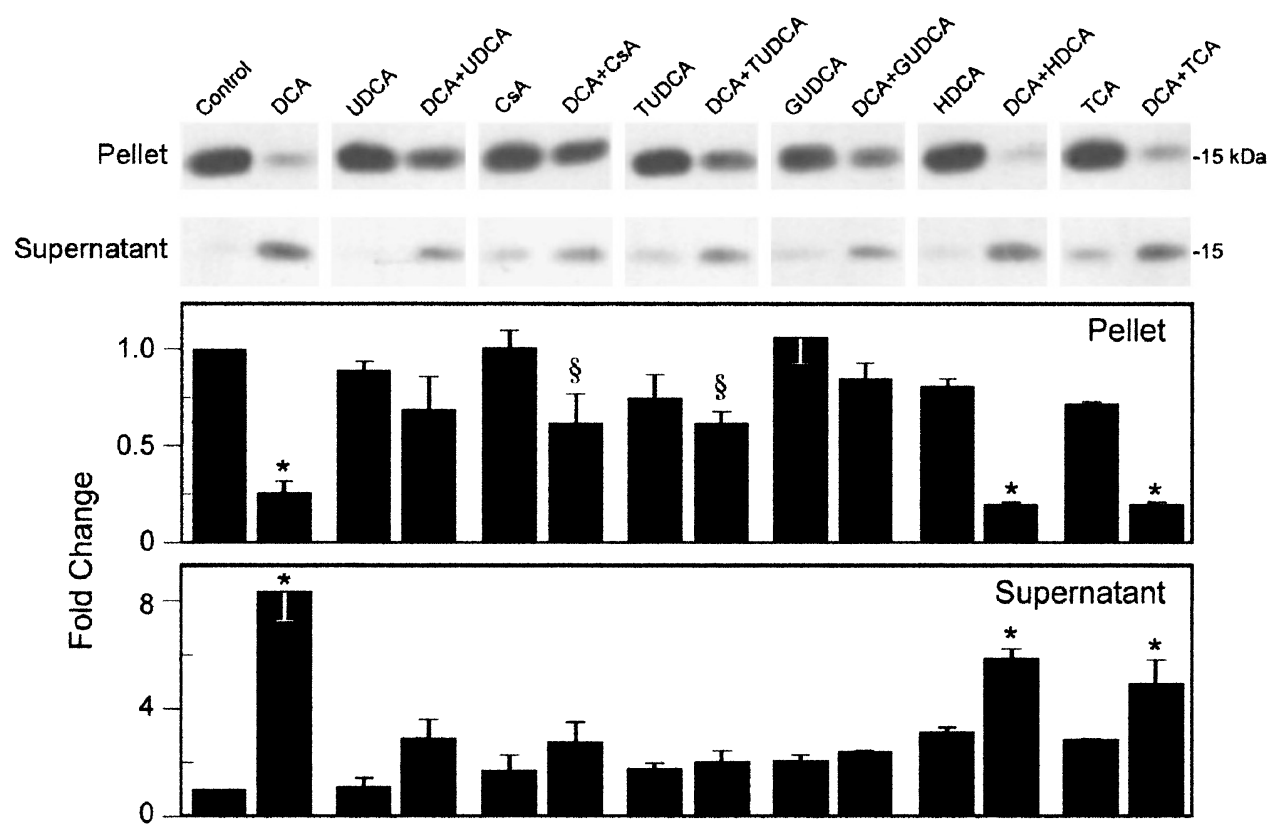

Figure 3 UDCA inhibits DCA-induced release of cytochrome $c$ in isolated mitochondria after MPT. Mitochondria were isolated and incubated (1 mg/ml) with either no addition (control), $250 \mu \mathrm{M} \mathrm{DCA}, 500 \mu \mathrm{M}$ UDCA, DCA+UDCA, $5 \mu \mathrm{M}$ cyclosporine A (CsA), DCA+CsA, $500 \mu \mathrm{M}$ tauroursodeoxycholic acid (TUDCA), DCA+TUDCA, $500 \mu \mathrm{M}$ glycoursodeoxycholic acid (GUDCA), DCA+GUDCA, $500 \mu \mathrm{M}$ hyodeoxycholic acid (HDCA), DCA+HDCA, $500 \mu \mathrm{M}$ taurocholic acid (TCA), or DCA+TCA in respiration buffer as described in Materials and Methods. The mitochondrial pellets and supernatants were examined for cytochrome $c$ levels by Western blot analysis (top panels). Following SDS-PAGE and transfer, the nitrocellulose membranes were incubated with the monoclonal antibody to cytochrome $c$ and the $15 \mathrm{kDa}$ protein was detected using $\mathrm{ECL}$ chemiluminescence. The accompanying histograms are the densitometric means \pm S.E.M. relative to controls from at least three independent experiments (bottom panels). $\S P<0.05$ from control and DCA; ${ }^{*} P<0.001$ from control. No other significant changes were observed from control values

\section{Okadaic acid and TGF- $\beta 1$ induce release of cytochrome $c$, activation of DEVD-specific caspases and cleavage of PARP}

We next determined whether okadaic acid or TGF- $\beta 1$ could induce the release of cytochrome $c$ from mitochondria in cultured hepatocytes during apoptosis. The results indicated that control cells contained almost no detectable cytosolic cytochrome $c$ protein. In contrast, incubation of hepatocytes with either okadaic acid or TGF- $\beta 1$ induced a progressive release of cytochrome $c$ from mitochondria (Figure $4 \mathrm{Aa}, \mathrm{Ba}$ ). Significant accumulation of cytochrome $c$ in the cytosol occurred after $2 \mathrm{~h}$ of incubation with okadaic acid. The maximum release of cytochrome $c$ from mitochondria was observed at $8 \mathrm{~h}$ and no further increases were observed through $24 \mathrm{~h}$. Similar results were obtained for cells incubated with TGF- $\beta 1$, where cytosolic accumulation of cytochrome $c$ was detectable at $4 \mathrm{~h}$ and continued to increase until $16 \mathrm{~h}$. Although less dramatic, cytosolic cytochrome $c$ levels were also significantly increased $(P<0.05)$ after $4 \mathrm{~h}$ of incubation with DCA. Thus, for each of the apoptotic inducing agents, maximal cytochrome $c$ release preceded the peak morphologic nuclear changes determined by Hoechst staining (Figure 1).

Cytosolic extracts were also tested for their ability to cleave the chromophore pNA from the peptide caspase substrate DEVD-pNA. Caspase activity was significantly increased by $4 \mathrm{~h}$ after treatment with okadaic acid
$(P<0.01)$, with maximum levels at $16 \mathrm{~h} \quad(P<0.001)$ (Figure 4Ab). Similarly, $1 \mathrm{nM}$ TGF- $\beta 1$ induced a significant increase in caspase activity at $16 \mathrm{~h}$ $(P<0.01)$, and no further increase was observed after $30 \mathrm{~h}(P<0.001)$ (Figure 4Bb). Finally, at $6 \mathrm{~h}$, DCA induced a detectable increase in caspase activity $(P<0.05)$. We next determined the effect of okadaic acid and TGF- $\beta 1$ on the cleavage of an endogenous caspase-3 $116 \mathrm{kDa}$ substrate, PARP. Incubation of hepatocytes with okadaic acid resulted in a marked increase in the $85 \mathrm{kDa}$ cleavage product at $4 \mathrm{~h}$, and this continued to increase with nearly complete cleavage at $24 \mathrm{~h}$ (Figure 4Ac). Degradation of this nuclear enzyme was also evident within $16 \mathrm{~h}$ of incubation of cells with TGF- $\beta 1$ and continued to increase until $30 \mathrm{~h}$ (Figure $4 \mathrm{Bc})$.

\section{Reduced $\Delta \psi_{\mathrm{m}}$ coincides with mitochondrial release of cytochrome $c$ in okadaic acid- and TGF- $\beta 1$-induced apoptosis}

It has been shown that the mitochondrial release of cytochrome $c$ into the cytosol results from opening of the MPT pore. ${ }^{20-22,24,25}$ This is associated with collapse of the $\Delta \psi_{\mathrm{m}}$, which can be measured by a reduced mitochondrial accumulation of the fluorescent dye DiOC $_{6}(3) .^{41,42}$ After $2 \mathrm{~h}$ of exposure to okadaic acid, a significant decrease in the retention of $\mathrm{DiOC}_{6}(3)$ was observed $(P<0.05)$, and the decline continued until $8 \mathrm{~h}$ 
$(P<0.001)$ with only minor changes thereafter (Figure 4Ad). Similarly, incubation with TGF- $\beta 1$ induced a significant $(P<0.001)$ decrease in $\Delta \psi_{\mathrm{m}}$ by $6 \mathrm{~h}$, with only minor additional changes through $40 \mathrm{~h}$ (Figure 4Bd). Incubation of hepatocytes with DCA also induced a small, but significant decrease in $\Delta \psi_{\mathrm{m}}(P<0.05)$ resulting in cytochrome $c$ release. Taken together, these results indicate that in primary hepatocytes treated with either okadaic acid or TGF- $\beta 1$, the onset of MPT coincides with mitochondrial release of cytochrome $c$, and appears to precede caspase activation, PARP cleavage and nuclear fragmentation.
A

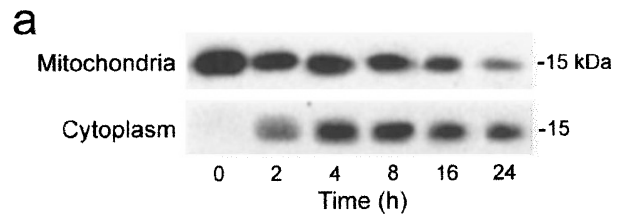

b

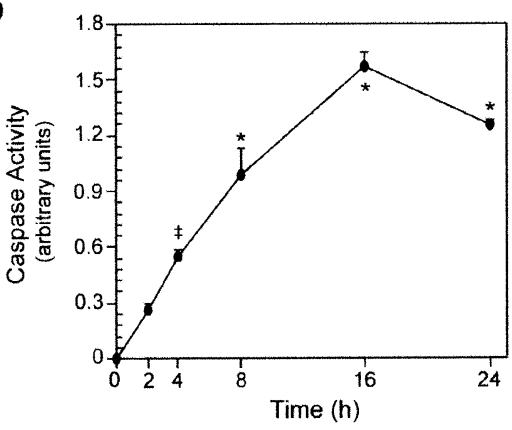

C

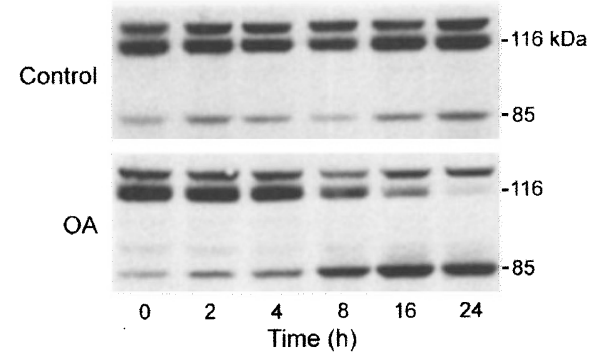

d

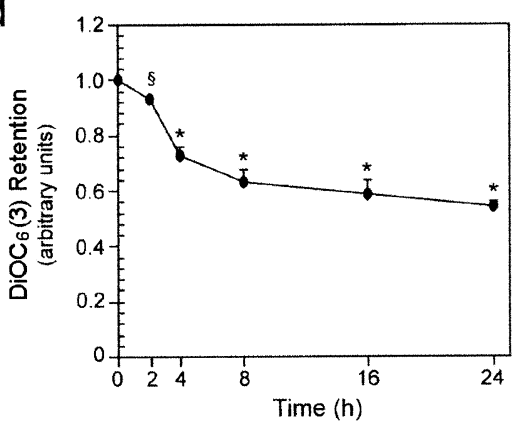

B

a

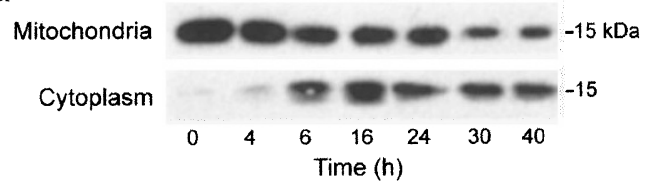

b

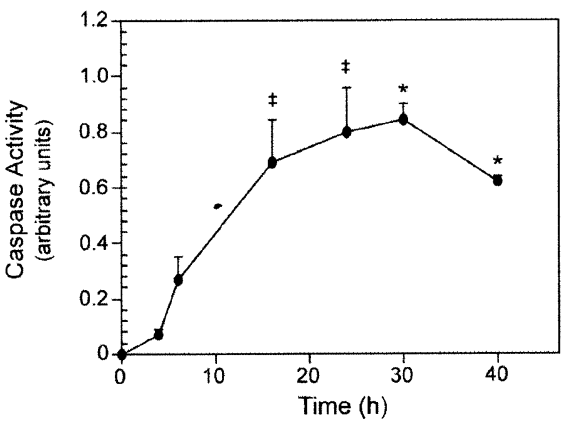

C

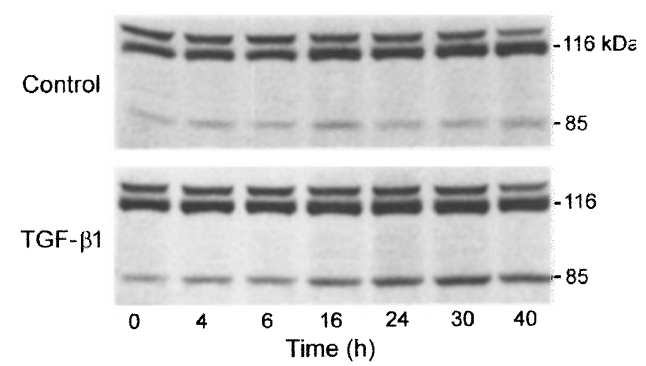

d

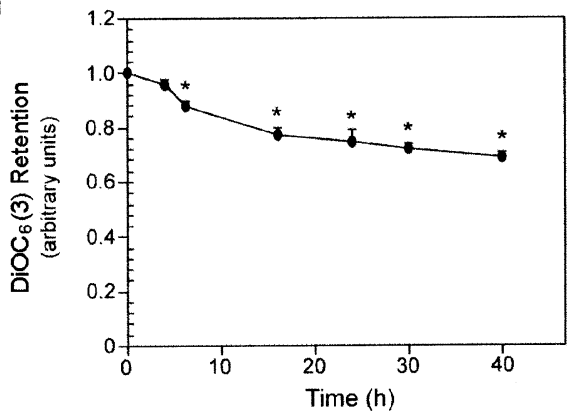

Figure 4 Mitochondrial release of cytochrome $c$ occurs prior to activation of DEVD-specific caspases and cleavage of PARP, and coincides with a reduction in $\Delta \psi_{\mathrm{m}}$ in hepatocytes incubated with okadaic acid (OA) (A) and TGF- $\beta 1$ (B). Cells were incubated with $25 \mathrm{nM}$ OA or $1 \mathrm{nM}$ TGF- $\beta 1$ for the indicated time points, as described in Materials and Methods. (a) Western blot analysis of cytochrome $c$ protein levels in mitochondrial and cytosolic fractions. Following SDS-PAGE and transfer, the nitrocellulose membranes were incubated with a monoclonal antibody to cytochrome $c$ and the protein was detected using ECL chemiluminescence. (b) DEVD-specific caspase activity in cytosolic fractions after incubation with OA or TGF- $\beta 1$. Activity was measured using the colorimetric substrate DEVD-pNA as described in Materials and Methods. (c) PARP cleavage in total protein extracts and detection of the 116 and $85 \mathrm{kDa}$ subunits by Western blot analysis. Following SDS-PAGE and transfer, the nitrocellulose membranes were incubated with a polyclonal antibody to PARP and the protein was detected by ECL chemiluminescence. (d) $\Delta \psi_{\mathrm{m}}$ in intact cells after incubation with OA or TGF- $\beta 1 . \Delta \psi_{\mathrm{m}}$ collapse was measured as the retention of the fluorescent dye DiOC 6 (3) added to cells during the last $30 \mathrm{~min}$ of incubation with OA or TGF- $\beta 1$. The graph data are means \pm S.E.M. of at least three different experiments. $\S P<0.05 ; \$ P<0.01$; ${ }^{*} P<0.001$ from time zero 
UDCA inhibits cytochrome $c$ release, DEVD-specific caspase activation, PARP cleavage and nuclear fragmentation

Incubation of primary rat hepatocytes with UDCA alone produced no significant changes in cytochrome $c$ release, caspase activation or PARP cleavage from controls (Figures 5 and 6). However, coincubation with UDCA protected against DCA-induced release of cytochrome $c$, reducing cytoplasmic levels to control values $(P<0.05)$ (Figure $5 \mathrm{~A})$. Furthermore, UDCA significantly inhibited the increase in DEVD-specific caspase activity and PARP cleavage associated with DCA alone $(P<0.001)$ (Figure 5B,C). UDCA was also effective in preventing the apoptotic changes induced by okadaic acid and TGF- $\beta 1$. The fourfold increase in cytosolic cytochrome $c$ that occurred after a $16 \mathrm{~h}$ incubation with okadaic acid was essentially inhibited by coincubation with UDCA (Figure 6Aa).

A

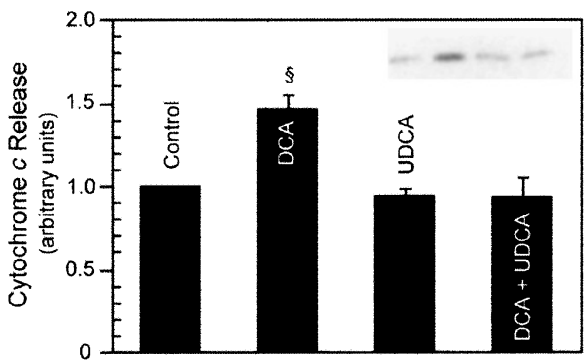

B
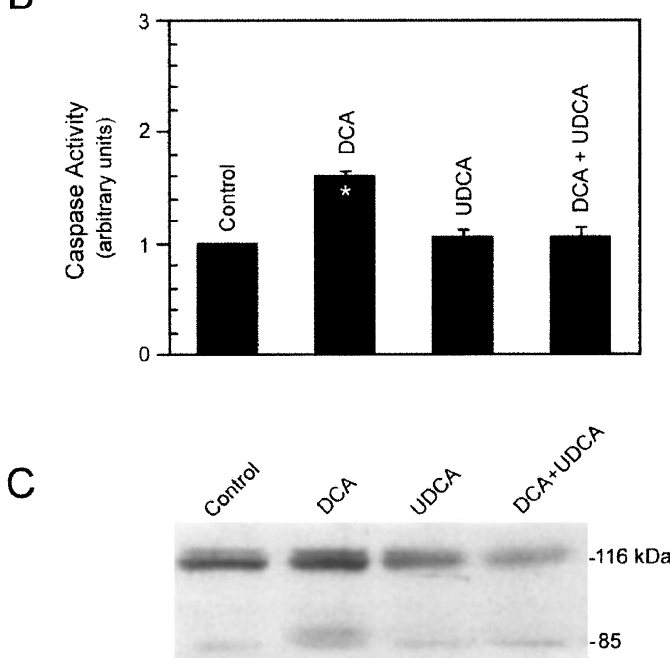

Figure 5 UDCA inhibits DCA-induced cytochrome $c$ release, DEVD-specific caspase activation, PARP cleavage and nuclear fragmentation in rat hepatocytes. Cells were incubated with either no addition (control), $50 \mu \mathrm{M}$ DCA, $100 \mu \mathrm{M}$ UDCA, or a combination of DCA+UDCA for $6 \mathrm{~h}$, as described in Materials and Methods. (A) Cytochrome $c$ levels in mitochondria and cytosolic fractions after incubation with DCA, UDCA, the combination, or no addition. Inset, top, a representative Western blot of cytosolic cytochrome $c$ expression. (B) DEVD-specific caspase activity in cytosolic fractions measured using the colorimetric substrate DEVD-pNA. (C) Western blot analysis of PARP cleavage in total protein extracts after incubation with the bile acids. The histograms are means \pm S.E.M. from a minimum of three experiments. $\S P<0.05 ;{ }^{*} P<0.001$ from all others at the same time point. No significant changes were observed between control, UDCA, and DCA plus UDCA
Although the addition of UDCA did not entirely prevent okadaic acid-induced caspase activation and PARP cleavage, both were reduced by $55-75 \%(P<0.001)$ (Figure $6 A b, c)$. Similarly, UDCA inhibited the release of cytochrome $c$ in hepatocytes incubated with TGF- $\beta 1$, as well as reduced the caspase activity and PARP cleavage by almost $70 \%$ (Figure $6 \mathrm{Ba}-\mathrm{c})$. These results compared favorably with the morphologic inhibition of apoptosis by UDCA (Table 1).

Our results suggested that common anti-apoptotic events are specifically modulated by UDCA. We considered that UDCA might act by preventing both the swelling and channel-forming activity of the mitochondrial membrane. Therefore, to establish modulation of UDCA, $\Delta \psi_{\mathrm{m}}$ was measured in rat hepatocytes using the fluorescent dye $\mathrm{DiOC}_{6}(3) . \Delta \psi_{\mathrm{m}}$ was significantly decreased after induction of apoptosis not only with DCA, but also with okadaic acid and TGF- $\beta 1$ (Figure 6Ad,Bd). Coincubation with UDCA resulted in a $50-60 \%$ inhibition of the mitochondrial depolarization $(P<0.05)$ associated with all three agents. Interestingly, this level of protection by UDCA could not entirely account for the inhibitory effect on apoptosis by DCA, okadaic acid or TGF- $\beta 1$ (Table 1). Therefore, we next investigated the effect of these agents on translocation of the pro-apoptotic Bax protein from cytosol to mitochondrial membrane. In fact, Western blot analysis of mitochondrial proteins revealed increased levels of Bax. This change coincided with a similar decrease in cytosolic levels of Bax protein, and was particularly pronounced for okadaic acidand TGF- $\beta 1$-induced apoptosis (Figure 7). Coincubation with UDCA resulted in a $30-40 \%$ decrease in Bax translocation from cytosol to the mitochondria in the cultured hepatocytes.

\section{Discussion}

Pharmacologic doses of UDCA markedly improve the outcome of certain liver diseases through mechanisms which are not entirely understood. ${ }^{6}$ It was a particularly important observation then, when UDCA was shown to inhibit the MPT induced by glycochenodeoxycholic acid. ${ }^{11}$ In fact, UDCA appears to regulate apoptosis in both hepatic and nonhepatic cells by preventing mitochondrial depolarization and reactive oxygen species production. ${ }^{10,13}$ Interestingly, the ability of UDCA to inhibit apoptosis appears to be independent of the inducing agent and its pathway, suggesting a common antiapoptotic mechanism(s). In particular, while the pathway to execution may be more direct with DCA, the apoptosis from TGF- $\beta 1$ and okadaic acid are equally sensitive to the inhibitory effects of UDCA. It remains to be determined if UDCA acts at additional sites other than mitochondria in these apoptotic pathways.

The present study demonstrates that cytochrome $c$ is released from mitochondria of primary rat hepatocytes in response to incubation with DCA, okadaic acid and TGF$\beta 1$. Cytochrome $c$ release has been shown to be a common event in the cell death effector pathway initiated by diverse apoptosis-inducing agents. ${ }^{16-18,35,42}$ However, the precise mechanism responsible for cytochrome $c$ efflux from mitochondria into cytosol remains controversial. Recent studies reported that release of cytochrome $c$ 
occurs independently of the MPT and without accompanying mitochondrial depolarization. ${ }^{17,18}$ In contrast, our results with isolated mitochondria indicate that the onset of MPT by DCA not only precedes but is essential for cytochrome $c$ release. For example, cyclosporine $A$ not only blocked MPT but also prevented mitochondrial swelling and reduced the efflux of cytochrome $c$ with
DCA. Moreover, incubation of mitochondria with phenylarsine oxide, an inducer of MPT, also resulted in significant release of cytochrome $c$, which was markedly inhibited by UDCA. Finally, the release of cytochrome $c$ in hepatocytes incubated with okadaic acid or TGF- $\beta 1$ coincided with mitochondrial depolarization, an event that follows the onset of the MPT.
A

a

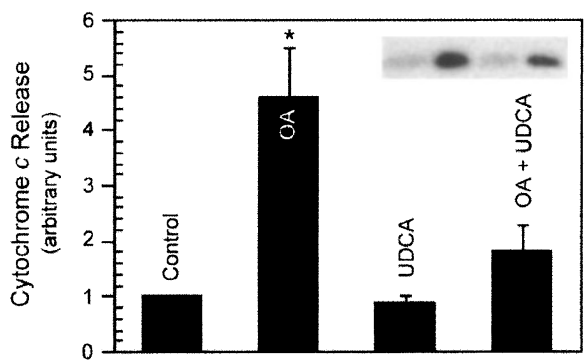

b

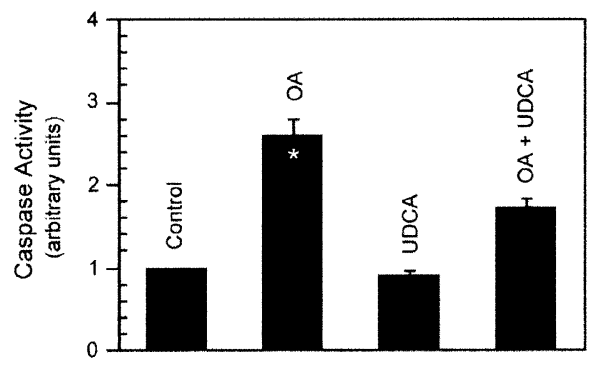

C

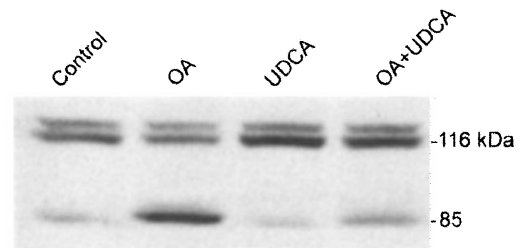

d

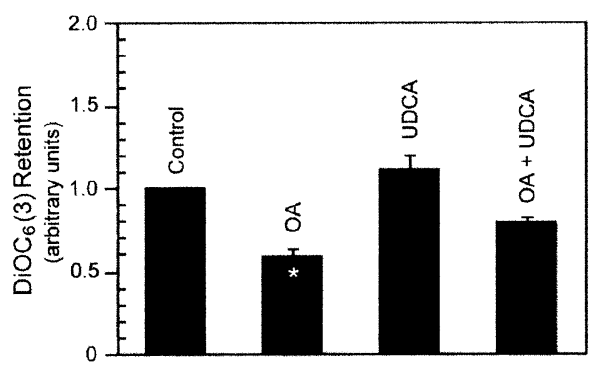

a

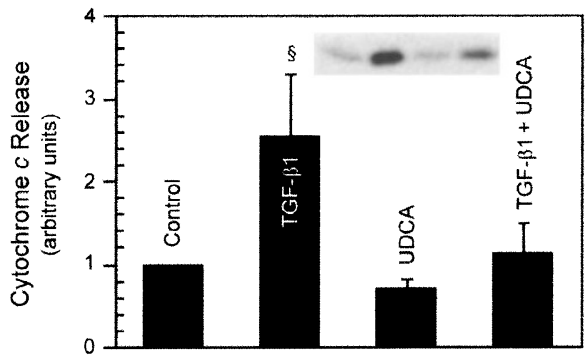

b

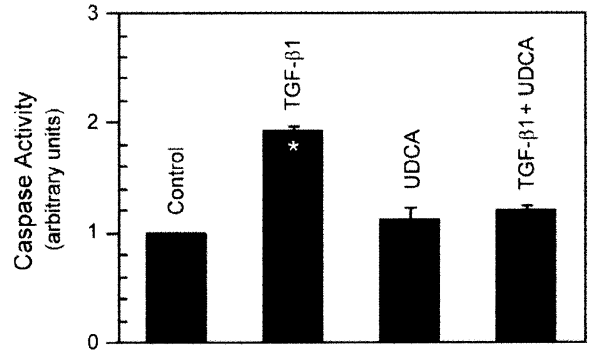

C

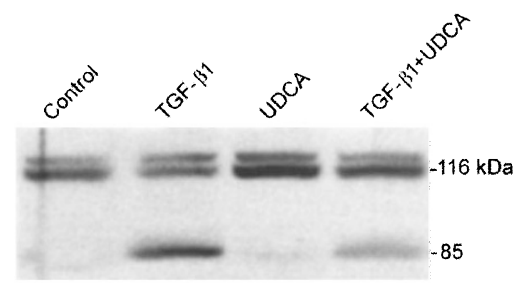

d

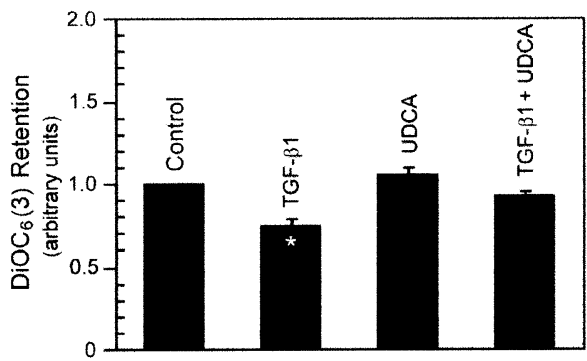

Figure 6 UDCA decreases cytochrome $c$ release, DEVD-specific caspase activation, PARP cleavage and nuclear fragmentation by inhibiting mitochondrial depolarization in rat hepatocytes incubated with okadaic acid (OA) (A) and TGF- $\beta 1$ (B). Cells were incubated with either no addition (control), $100 \mu \mathrm{M}$ UDCA, $25 \mathrm{nM}$ OA for $16 \mathrm{~h}, 1 \mathrm{nM}$ TGF- $\beta 1$ for $24 \mathrm{~h}$, or a combination of TGF- $\beta 1$ plus UDCA, as described in Materials and Methods. (a) Cytochrome $c$ levels in mitochondrial and cytosolic fractions after incubation with OA or TGF- $\beta 1$, UDCA, the combination, or no addition. Inset, top, representative Western blots of cytosolic cytochrome $c$ expression. (b) DEVD-specific caspase activity in cytosolic fractions measured using the colorimetric substrate DEVD-pNA after incubation with OA or TGF- $\beta 1$. (c) Western blot analysis of PARP cleavage in total protein extracts. (d) $\Delta \psi_{\mathrm{m}}$ measured as the retention of the fluorescent dye $\mathrm{DiOC}_{6}(3)$ added to cells during the last 30 min of incubation with OA, TGF- $\beta 1$, UDCA, the combination, or no addition. The histograms are means \pm S.E.M. from a minimum of three experiments. $\$ P<0.05$; ${ }^{*} P<0.001$ from all others at the same time point. No significant changes were observed between control, UDCA, and OA or TGF- $\beta 1$ plus UDCA 
Our results demonstrating a role for MPT in hepatocyte apoptosis agree with those obtained from isolated mitochondria induced to undergo MPT and the consequent reduction in $\Delta \psi_{\mathrm{m}}{ }^{21,26,36,43}$ Furthermore, various inhibitors of the MPT not only suppressed the mitochondrial release of a $50 \mathrm{kDa}$ apoptosis-inducing factor but also blocked the associated nuclear changes. ${ }^{43}$ Our data indicate that the magnitude of the reduction in $\Delta \psi_{\mathrm{m}}$ correlates with the percentage of cells exhibiting morphologic changes of apoptosis. Additionally, the MPT in hepatocytes occurs upstream from caspase DEVD-specific activation and PARP cleavage and coincides with cytochrome $c$ release. This is in agreement with previous studies demonstrating that cytochrome $c$ release is required for caspase activation. ${ }^{14,15,44,45}$ When isolated mitochondria or cultured cells were exposed to UDCA alone, no significant MPT, morphologic change or efflux of cytochrome $c$ was observed. However, coincubation with UDCA dramatically inhibited the changes associated with the apoptotic agents, implying that UDCA functions primarily by blocking the MPT. Taken together, our results suggest that the efflux of cytochrome $c$ is, in part, a consequence of MPT-induced mitochondrial swelling and outer membrane rupture. Moreover, the onset of MPT and coincident release of cytochrome $c$ clearly precedes and is required for caspase activation, PARP cleavage and nuclear condensation and fragmentation associated with all three apoptotic agents. The recent observation that Z-Val-Ala-Asp-fluoromethyl ketone inhibits caspase- 3 activation in bile salt-induced apoptosis and prevents subsequent cathepsin B activation and apoptosis supports the temporal nature of these events in hepatocytes undergoing apoptosis. ${ }^{46}$

In our study, less than a $40 \%$ decrease in $\Delta \psi_{\mathrm{m}}$ was observed in hepatocytes incubated with DCA, okadaic acid or TGF- $\beta 1$. In contrast, a much greater percentage of cytochrome $c$ was released from mitochondria during

Table 1 Inhibition of apoptosis, cytochrome $c$ release, mitochondrial depolarization and Bax translocation by UDCA

\begin{tabular}{|c|c|c|c|c|c|c|}
\hline \multirow[b]{2}{*}{$\begin{array}{l}\text { Inducer } \\
\text { (Incubation time) }\end{array}$} & \multicolumn{6}{|c|}{ Inhibition (\%) } \\
\hline & $\begin{array}{c}\text { Nuclear } \\
\text { fragmentation }\end{array}$ & $\begin{array}{c}\text { Cytochrome } c \\
\text { release }\end{array}$ & $\begin{array}{l}\text { Caspase } \\
\text { activity }\end{array}$ & $\begin{array}{c}\text { PARP } \\
\text { cleavage }\end{array}$ & $\begin{array}{c}\Delta \Psi \mathrm{m} \\
\text { collapse }\end{array}$ & $\begin{array}{c}\text { Bax } \\
\text { translocation }\end{array}$ \\
\hline Deoxycholic acid (6 h) & $81.0 \pm 3.2$ & $75.7 \pm 4.9$ & $76.6 \pm 11.8$ & $70.1 \pm 3.6$ & $61.6 \pm 9.7$ & $18.2 \pm 1.2^{*}$ \\
\hline Okadaic acid (16 h) & $77.6 \pm 1.2$ & $71.5 \pm 7.1$ & $56.5 \pm 2.4 \S$ & $74.6 \pm 7.2$ & $49.5 \pm 3.9 \%$ & $41.3 \pm 4.7^{*}$ \\
\hline TGF- $\beta 1(24 \mathrm{~h})$ & $80.1 \pm 1.6$ & $68.8 \pm 9.2$ & $72.8 \pm 5.2$ & $69.7 \pm 2.5$ & $57.8 \pm 9.0$ & $31.5 \pm 2.1^{*}$ \\
\hline
\end{tabular}

Data calculated as mean \pm S.E.M. from Figures 1 and $4-7$. Statistically significant decrease from per cent inhibition of nuclear fragmentation $(\S P<0.05$; $₫ P<0.01$; and $\left.{ }^{\star} P<0.001\right)$

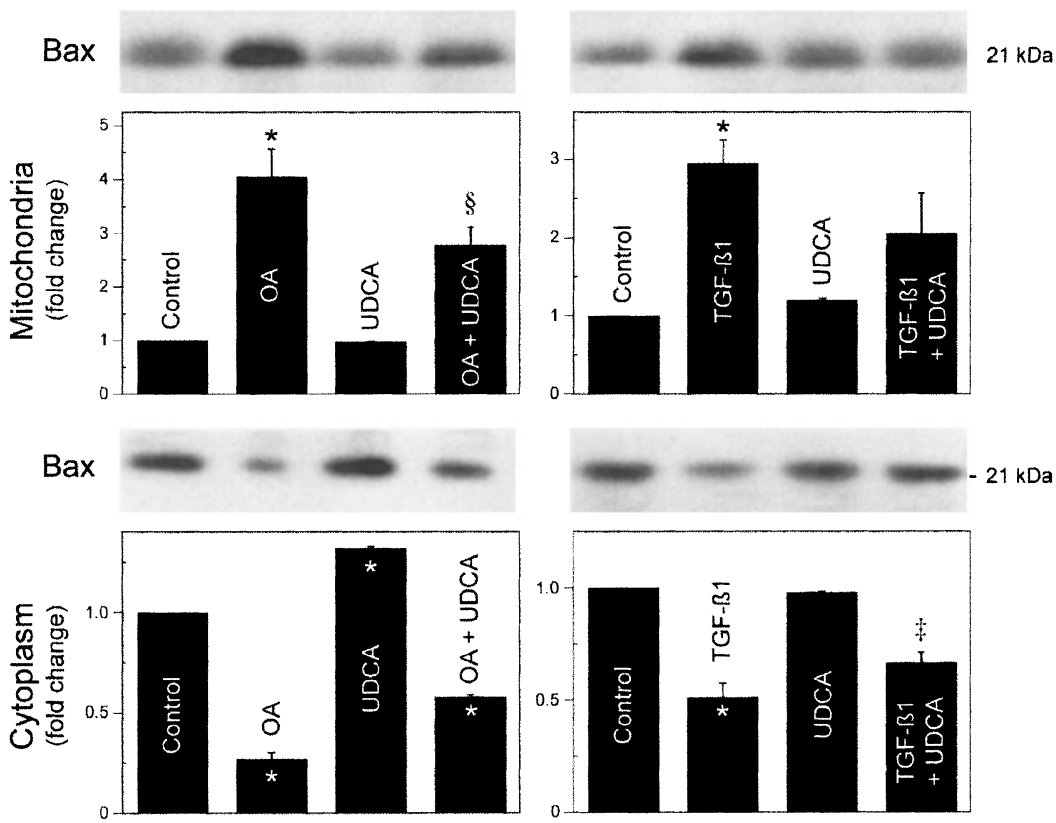

Figure 7 UDCA modulates redistribution of the pro-apoptotic protein Bax from the cytosol to the mitochondrial membrane in rat hepatocytes exposed to okadaic acid (OA) or TGF- $\beta 1$. Cells were incubated with either $25 \mathrm{nM} \mathrm{OA}$ (left), $1 \mathrm{nM}$ TGF- $\beta 1$ (right), $100 \mu \mathrm{M}$ UDCA, a combination of inducer plus UDCA, or no addition (control), as described in Materials and Methods. Mitochondrial (top panel) and cytosolic (bottom panel) proteins from cells incubated with OA or TGF- $\beta 1$ were processed for Western blot analysis. Following SDS-PAGE and transfer, the nitrocellulose membranes were incubated with a polyclonal antibody to Bax and the $21 \mathrm{kDa}$ protein was detected using ECL chemiluminescence. The accompanying histograms are the densitometric means \pm S.E.M. relative to controls of at least three separate experiments. $\S P<0.05$ and ${ }^{*} P<0.001$ from control or $O A ; \ddagger P<0.01$ from control. No other significant changes were observed between control and UDCA 
apoptosis, suggesting efflux by alternate mechanisms. In rat hepatocytes expressing an $\mathrm{I}_{\kappa} \mathrm{B}$ superrepressor, tumor necrosis factor alpha induced depolarization of mitochondria and MPT. Initially, the effect was observed only in a subgroup of mitochondria, and only after several hours was it detectable in the entire population. ${ }^{47}$ Thus, hepatocytes undergoing apoptosis contain both polarized and depolarized mitochondria, and each subpopulation may be a source of cytochrome $c$ efflux. This may explain the recent observation that cytochrome $c$ is released in cells independently of detectable mitochondrial transmembrane depolarization. ${ }^{35}$ Alternatively, multiple signaling pathways may be induced by a single apoptotic stimulus, as was recently suggested to occur during Fas-mediated apoptosis. ${ }^{48}$ In this regard, it has been demonstrated that overexpression of Bax or Bak initiates cell death and correlates with mitochondrial cytochrome $c$ release into the cytosol and induction of MPT. 30,31,49-51

Although the mechanism of Bax function is not entirely understood, it appears to affect Bcl-2-mediated events via heterodimeric modulation. In the absence of a death signal, Bax is found in association with mitochondria, as well as distributed throughout the cytoplasmic and perinuclear regions. $^{52,53}$ However, during apoptosis Bax itself is actively translocated to the mitochondrial membrane, ${ }^{54-57}$ where it is capable of autonomous pore formation ${ }^{58,59}$ and mediates membrane dysfunction. This Bax induced perturbation results in the release of cytochrome $c$, production of reactive oxygen species, loss of $\Delta \psi_{\mathrm{m}}$, and induction of MPT ultimately culminating in cell death. 24,25,60 Interestingly, pro-apoptotic Bax can trigger the release of cytochrome $c$ in the absence of MPT and the mitochondrial swelling that precedes rupture of the outer membrane. ${ }^{38,39}$

Our data demonstrate that translocation of Bax from the cytosol to the mitochondria occurs during apoptosis in primary hepatocytes. The extent of translocation correlates with the percentage of cells undergoing apoptosis, and the event is partially prevented by coincubation with UDCA. Furthermore, the per cent reduction in apoptosis by UDCA is similar to the additive effects of inhibiting both $\Delta \psi_{\mathrm{m}}$ collapse and Bax translocation from cytosol to mitochondria. This suggests that the mechanism of UDCA protection may, in fact, involve an interplay of events, whereby both depolarization and channel-forming activity of the mitochondrial membrane together with cytochrome $c$ release are reduced. Moreover, cytochrome $c$ leakage through the opened MPT pore may also contribute to efflux of cytochrome $c$ through a Bax-dependent event, thereby creating self-amplifying loops. In support of this model, a recent study demonstrated that stimulation of $\mathrm{Bax}$ mitochondrial targeting with cell extracts requires cytochrome $c .^{55}$ Therefore, disruption of the outer membrane as a consequence of MPT pore opening may be responsible for the initial cytochrome $c$ release from mitochondria. This, in turn, could stimulate Bax translocation to the mitochondria and a subsequent amplification of cytochrome $c$ efflux via a Bax-mediated process. Such an event may also be initiated by signal transduction in which Bax, as a consequence of its pore-forming properties, triggers release of cytochrome $c$, activation of caspases and subsequent Bax targeting to mitochondria. Interestingly, incubation of recombinant Bax with isolated liver mitochondria induced release of cytochrome $c$ in the absence of membrane depolarization and induction of MPT. ${ }^{61}$ This would suggest that the additive effects of UDCA on cytochrome $c$ release results from modulating both Bax translocation and MPT in hepatocyte mitochondria.

From this study, UDCA or its conjugated derivatives directly interfere with MPT pore opening in isolated mitochondria, thereby reducing efflux of cytochrome $c$. This is a unique property of UDCA unrelated to its hydrophilicity since neither hyodeoxycholic nor taurocholic acid exhibit this protection. It remains to be determined, however, whether inhibition of mitochondrial Bax translocation by UDCA in cells is mediated by direct interaction with Bax, or indirectly through other cytosolic or membrane proteins. Perhaps UDCA prevents Bax activity by binding to its C-terminal hydrophobic domain, which is believed to be responsible for anchoring Bax to membranes. ${ }^{29,57}$ Alternatively, interaction with UDCA might alter the conformational state of Bax. In fact, the protein displays several distinct detergent-induced conformations which allow varying degrees of Bax hetero- and homodimerization within the membrane. ${ }^{62,63}$ The ability of UDCA to inhibit cytosolic Bax translocation demonstrated in this study is not without precedent. In vivo DCA feeding was associated with a 4.5-fold increase in mitochondrial-associated Bax protein levels, while combination feeding with UDCA significantly inhibited these changes. ${ }^{13}$ Like Bcl-2, UDCA appears to modulate Bax-induced events at several levels, including prevention of Bax redistribution, inhibition of cytochrome $c$ release, and modulation of cytochrome $c$ mediated downstream events such as DEVD-specific caspase activity and PARP cleavage. It remains to be determined whether other factors, such as Bid-induced conformational change of Bax and cytochrome $c$ release, ${ }^{64}$ are in some way modulated by UDCA.

In conclusion, our data indicate that UDCA inhibits hepatocyte apoptosis by modulating mitochondrial membrane perturbation, Bax translocation and cytochrome $c$ release. Moreover, the data support a unique role for UDCA in preventing the release of cytochrome $c$ from mitochondria, DEVD-specific caspase activation in cytosol, and cleavage of the nuclear enzyme PARP in primary rat hepatocytes incubated with DCA, TGF- $\beta 1$ or okadaic acid. Although the precise details remain to be elucidated, the mechanism appears to involve direct inhibition of mitochondrial depolarization by preventing MPT, together with modulation of channel-forming activity associated with Bax translocation. The results suggest a heretofore unrecognized and perhaps essential role for bile acids in the regulation of cell survival.

\section{Materials and Methods}

\section{Hepatocyte isolation and cell culture}

Rat primary hepatocytes were isolated from male Sprague-Dawley rats $(200-250 \mathrm{~g})$ by collagenase perfusion as described previously. ${ }^{65}$ Briefly, rats were anesthetized with phenobarbitol and the livers were 
perfused with $0.05 \%$ collagenase. Hepatocyte suspensions were obtained by passing digested livers through $125 \mu \mathrm{m}$ gauze and washing cells in modified Eagle's medium (MEM) (Atlanta Biologicals, Inc., Norcross, GA, USA). Cell viability was determined by trypan blue exclusion and was typically $85-90 \%$. After isolation, hepatocytes were resuspended in William's E medium (Life Technologies, Inc., Grand Island, NY, USA) supplemented with $26 \mathrm{mM}$ sodium bicarbonate, $23 \mathrm{mM}$ HEPES, $0.01 \mathrm{U} / \mathrm{ml}$ insulin, $2 \mathrm{mM}$ L-glutamine, $10 \mathrm{nM}$ dexamethasone, $5.5 \mathrm{mM}$ glucose, $100 \mathrm{U} / \mathrm{ml}$ penicillin and $100 \mathrm{U} / \mathrm{ml}$ streptomycin and then plated on $35 \times 10 \mathrm{~mm}$ Primaria ${ }^{\text {III }}$ tissue culture dishes (Becton Dickinson Labware, Lincoln Park, NJ, USA) at $1.0 \times 10^{6}$ cells $/ \mathrm{ml}$. The cells were maintained at $37^{\circ} \mathrm{C}$ in a humidified atmosphere of $5 \% \mathrm{CO}_{2}$ for $3 \mathrm{~h}$. Plates were then washed with medium to remove dead cells, and William's $\mathrm{E}$ medium containing $10 \%$ heat-inactivated FBS $\left(56^{\circ} \mathrm{C}\right.$ for $\left.30 \mathrm{~min}\right)$ was added (Atlanta Biologicals, Inc.).

\section{Induction of apoptosis}

Freshly isolated rat hepatocytes were cultured for $3 \mathrm{~h}$ as described above and then incubated with William's $E$ medium supplemented with either $50 \mu \mathrm{M}$ DCA (Sigma Chemical Co., St. Louis, MO, USA) for 2$6 \mathrm{~h}, 25 \mathrm{nM}$ okadaic acid (Boehringer Mannheim Biochemicals, Inc., Indianapolis, IN, USA) for $2-24 \mathrm{~h}$, or $1 \mathrm{nM}$ TGF- $\beta 1$ (R \& D Systems, Minneapolis, MN, USA) for $4-40 \mathrm{~h}$, with or without $100 \mu \mathrm{M}$ UDCA (Sigma Chemical Co.), or no addition (control). The medium was gently removed at the indicated time points and scored for nonviable cells by trypan blue dye exclusion, and the attached cells were fixed for morphologic assessment of apoptotic changes. In addition, cytosolic and mitochondrial fractions were prepared and evaluated for cytochrome $c$ release and Bax translocation. Finally, Asp-Glu-ValAsp (DEVD)-specific caspase activity and PARP cleavage were determined in cytosolic and total protein, respectively.

\section{Morphologic analysis}

Morphology was performed as described previously. ${ }^{66}$ Briefly, medium was gently removed at the indicated time points to prevent detachment of cells. Cells were fixed with $4 \%$ formaldehyde (wt/vol) in PBS, $\mathrm{pH} 7.4$, for $10 \mathrm{~min}$ at room temperature, incubated with Hoechst dye 33258 (Sigma Chemical Co.) at $5 \mathrm{mg} / \mathrm{ml}$ in PBS for $5 \mathrm{~min}$, washed with PBS and mounted using PBS: glycerol $(3: 1, v / v)$. Fluorescence was visualized with a Zeiss standard fluorescence microscope (Carl Zeiss, Inc., Thornwood, NY, USA). Photographs were taken with Kodak Ektar-1000 film (Eastman Kodak Co., Rochester, NY, USA). Stained nuclei were scored by blind analysis and categorized according to the morphologic characteristics of the chromatin. Apoptotic nuclei were identified by condensed chromatin contiguous to the nuclear membrane, as well as nuclear fragmentation and formation of apoptotic bodies. Normal nuclei were identified as noncondensed chromatin dispersed throughout the entire nucleus. Three fields per dish of approximately 500 nuclei were counted; mean values were expressed as the per cent of apoptotic nuclei.

\section{Cytochrome $c$ release and Bax translocation}

Cells at $1.0 \times 10^{7} / \mathrm{ml}$ were harvested by centrifugation at $600 \times \mathrm{g}$ for $5 \mathrm{~min}$ at $4{ }^{\circ} \mathrm{C}$. The cell pellets were washed once in ice-cold PBS and resuspended with three volumes of isolation buffer containing $20 \mathrm{mM}$ HEPES-KOH, pH 7.5, $10 \mathrm{mM} \mathrm{KCl}, 1.5 \mathrm{mM} \mathrm{MgCl} 2,1 \mathrm{mM}$ sodium EDTA, $1 \mathrm{mM}$ sodium EGTA, $1 \mathrm{mM}$ dithiothreitol (DTT), supplemented with the Complete ${ }^{(i x}$ protease inhibitor cocktail (Boehringer Mannheim
Biochemicals, Inc.) in $250 \mathrm{mM}$ sucrose. After chilling on ice for $15 \mathrm{~min}$, the cells were disrupted by 40 strokes of a glass homogenizer and the homogenates were centrifuged twice at $2500 \times g$ for $10 \mathrm{~min}$ at $4^{\circ} \mathrm{C}$ to remove unbroken cells and nuclei. The mitochondrial fraction was centrifuged at $12000 \times \mathrm{g}$ for $30 \mathrm{~min}$ at $4^{\circ} \mathrm{C}$, and the pellet resuspended in isolation buffer containing $250 \mathrm{mM}$ sucrose and frozen at $-80^{\circ} \mathrm{C}$. For cytosolic proteins, the $12000 \times g$ supernatants were removed, filtered through $0.2 \mu \mathrm{m}$ and then $0.1 \mu \mathrm{m}$ Ultrafree MC filters (Millipore Corporation, Bedford, MA, USA) and frozen at $-80^{\circ} \mathrm{C}$. Protein concentration was determined using the Bio-Rad protein assay kit according to the manufacture's specifications. Typically, 25 and $100 \mu \mathrm{g}$ of mitochondrial and 25 and $50 \mu \mathrm{g}$ of cytosolic proteins were separated on a $15 \%$ SDS-polyacrylamide electrophoresis gel for detection of cytochrome $c$ and Bax, respectively. Following electrophoretic transfer onto nitrocellulose membranes, the immunoblots were incubated with $15 \% \mathrm{H}_{2} \mathrm{O}_{2}$ for 15 min at room temperature. Blots were sequentially incubated with $5 \%$ milk blocking solution, primary monoclonal antibody to cytochrome $c$ (PharMingen, San Diego, CA, USA) at a dilution of $1: 5000$ overnight at $4{ }^{\circ} \mathrm{C}$, and finally with secondary goat anti-mouse IgG antibody conjugated with horseradish peroxidase (Bio-Rad Laboratories, Hercules, CA, USA) for $2 \mathrm{~h}$ at room temperature. In addition, blots were probed with primary polyclonal antibody to Bax (Santa Cruz Biotechnology, Santa Cruz, CA, USA) at a dilution of $1: 500$, and then with secondary antirabbit antibody conjugated with horseradish peroxidase (Bio-Rad Laboratories). The membranes were processed for detection of cytochrome $c$ and Bax using the ECL ${ }^{(i)}$ system from Amersham Life Science, Inc. (Arlington Heights, IL, USA). Mitochondrial contamination of the cytosolic protein extracts was determined by Western blot analysis of cytochrome $c$ oxidase (subunit II).

\section{Determination of DEVD-specific caspase activity and PARP cleavage}

The assay for detection of caspase activity is based on the ability of the enzyme to cleave the chromophore $\rho$-nitroanilide (pNA) from the enzyme substrate $N$-acetyl-Asp-Glu-Val-Asp-pNA (DEVD-pNA) (Sigma Chemical Co.). The proteolytic reaction was carried out in isolation buffer, containing $20 \mu \mathrm{g}$ of cytosolic protein and $50 \mu \mathrm{M}$ DEVD-pNA. The reaction mixtures were incubated at $37^{\circ} \mathrm{C}$ for $2 \mathrm{~h}$, and the formation of pNA was measured at $405 \mathrm{~nm}$ using a 96-well plate reader. To determine PARP cleavage, total homogenate protein was separated by $8 \%$ SDS-polyacrylamide gel electrophoresis. Blots were probed with primary polyclonal antibody to PARP (Santa Cruz Biotechnology) at a dilution of 1:2000, prior to incubation with secondary anti-rabbit antibody conjugated with horseradish peroxidase. Finally membranes were processed for PARP detection using the ECL ${ }^{(i m}$ system (Amersham Life Science, Inc.).

\section{Measurement of mitochondrial transmembrane potential}

Mitochondrial energization was determined as the retention of the dye $3^{\prime}, 3^{\prime}$-dihexyloxacarbocyanine $\left(\mathrm{DiOC}_{6}(3)\right.$; Molecular Probes Inc, Eugene, OR, USA). Primary rat hepatocytes were loaded with $100 \mathrm{nM} \mathrm{DiOC}_{6}(3)$ during the last $30 \mathrm{~min}$ of incubation with DCA, okadaic acid, or TGF- $\beta 1$ with or without UDCA. The culture medium was then removed, the cells were harvested by scraping and the cell pellet washed twice in ice-cold-PBS. The pellet was then lysed by the addition of $600 \mu \mathrm{l}$ of ice-cold MilliQ water (Millipore, Bedford, MA, USA) followed by homogenization. The concentration of retained 
$\mathrm{DiOC}_{6}(3)$ was read on a Perkin-Elmer LS-5 fluorescence spectrophotometer at $488 \mathrm{~nm}$ excitation and $500 \mathrm{~nm}$ emission.

\section{Isolation of mitochondria}

Low calcium liver mitochondria were isolated from adult male $200-$ $250 \mathrm{~g}$ Sprague-Dawley rats as previously described ${ }^{11,67}$ with modification. In short, animals were sacrificed by exsanguination under ether anesthesia and the livers removed and rinsed in normal saline. Approximately $10 \mathrm{~g}$ of minced liver was prepared as a $10 \%(\mathrm{wt} /$ vol) homogenate in an ice-cold solution of $70 \mathrm{mM}$ sucrose, $220 \mathrm{mM}$ mannitol, 1 mM EGTA and 10 mM HEPES, pH 7.4, at 800 r.p.m. using six complete strokes of a skill drill and teflon pestle (Tri-R Model K41, Tri-R Instruments, Rockville Center, NY, USA). The homogenate was centrifuged at $600 \times g$ for $10 \mathrm{~min}$ at $4^{\circ} \mathrm{C}$ in an SS-34 rotor in a Sorval RC5C centrifuge (Sorvall Instruments, Newtown, CT, USA), and the postnuclear supernatant was centrifuged at $7000 \times g$ for $10 \mathrm{~min}$ at $4^{\circ} \mathrm{C}$. The crude mitochondrial pellet was further purified by sucrosepercoll gradient centrifugation. ${ }^{68}$ The pellet was resuspended in $2 \mathrm{ml}$ of homogenate buffer, and $1 \mathrm{ml}$ of the resuspended pellet was carefully layered onto a $35-\mathrm{ml}$ self-generating gradient containing $0.25 \mathrm{M}$ sucrose, $1 \mathrm{mM}$ EGTA and percoll (Pharmacia Fine Chemicals, Piscataway, NJ, USA) $(75: 25, \mathrm{v} / \mathrm{v})$. The mitochondria were purified by centrifugation at $43000 \times g$ for 30 min at $4^{\circ} \mathrm{C}$ using a Beckman Ti60 rotor and a Beckman ultracentrifuge model L8-55 (Beckman Instruments, Inc., Schaumburg, IL, USA). The clear supernatant solution was removed and the lower turbid layer was resuspended in $30 \mathrm{ml}$ of wash buffer containing $0.1 \mathrm{M} \mathrm{KCl}, 5 \mathrm{mM} 3-(\mathrm{N}$-morpholino)propane sulfonic acid (MOPS), and $1 \mathrm{mM} \mathrm{EGTA}$, at $\mathrm{pH} 7.4$ and centrifuged at $7000 \times g$ for $10 \mathrm{~min}$ at $4^{\circ} \mathrm{C}$. The resulting mitochondrial pellet was washed twice more in this buffer and then a final wash in chelex-100-treated (400 mesh, potassium form, Bio-Rad Laboratories) buffer without EGTA. The pellet was suspended in $4 \mathrm{ml}$ of chelex-100treated resuspension buffer containing $125 \mathrm{mM}$ sucrose, $50 \mathrm{mM} \mathrm{KCl}$, $5 \mathrm{mM}$ HEPES, and $2 \mathrm{mM} \mathrm{KH}_{2} \mathrm{PO}_{4}$. A typical yield of mitochondria was approximately $25 \mathrm{mg}$ of protein per $\mathrm{gm}$ of liver tissue. Mitochondria were studied within $3 \mathrm{~h}$ of isolation, and assessed for purity as previously described. ${ }^{13}$

\section{Measurement of MPT and cytochrome $c$ levels}

The MPT was assessed using a spectrophotometric assay measuring high amplitude rapid changes in mitochondrial volume as described previously. ${ }^{11,69}$ Briefly, mitochondria (1 mg protein) were incubated in $1 \mathrm{ml}$ of chelex-100-treated respiration buffer $(0.1 \mathrm{M} \mathrm{NaCl}, 10 \mathrm{mM}$ MOPS, pH 7.4) for $10 \mathrm{~min}$ at $25^{\circ} \mathrm{C}$ and swelling was monitored at $540 \mathrm{nM}$ in a Beckman DU 64 spectrophotometer. Malate and glutamate $(1 \mathrm{mM})$ were added to initiate respiration, and $3 \mathrm{~min}$ later $5 \mu \mathrm{M}$ rotenone, an inhibitor of complex I of the respiratory chain, was also added to the suspension. Basal values of mitochondrial absorbance were measured for $5 \mathrm{~min}$, and the optical density was monitored for an additional 5 min after addition of either $200 \mu \mathrm{M} \mathrm{DCA}$, $125 \mathrm{nM}$ okadaic acid, $5 \mathrm{nM}$ TGF- $\beta 1$ or $80 \mu \mathrm{M}$ phenylarsine oxide (Sigma Chemical Co.). For the coincubation studies, mitochondria were preincubated with either $500 \mu \mathrm{M}$ UDCA, tauroursodeoxycholic acid, hyodeoxycholic acid, taurocholic acid (Sigma Chemical Co.), glycoursodeoxycholic acid (Steraloids Inc., Wilton, NH, USA) or $5 \mu \mathrm{M}$ cyclosporine A (Sigma Chemical Co.), for $5 \mathrm{~min}$ at $25^{\circ} \mathrm{C}$ prior to initiation of the assay. Following the MPT assays, mitochondria were centrifuged at $12000 \times \mathrm{g}$ for $3 \mathrm{~min}$ at $4^{\circ} \mathrm{C}$. Aliquots $(20 \mu \mathrm{l})$ of the supernatant and pellet were subjected to SDS-polyacrylamide gel electrophoresis for determination of cytochrome $c$ release.

\section{Electron microscopy}

Following the MPT assay, a portion of the mitochondrial pellet was fixed overnight at $4{ }^{\circ} \mathrm{C}$ in $0.1 \mathrm{M}$ cacodylate buffer $\mathrm{pH} 7.2$ containing $6 \%$ glutaraldehyde. The mitochondria were then rinsed with $0.1 \mathrm{M}$ PIPES buffer, $\mathrm{pH} 7.3$, followed by a 20 min postfix incubation at room temperature in $2 \%$ cacodylate-buffered $\mathrm{OsO}_{4}$. Next, the mitochondria were dehydrated using progressive concentrations of ethanol, infiltrated with propylene oxide, and embedded in Epon 812/Aralide 502 resin (Electron Microscopy Sciences, Fort Washington, PA, USA). Sections 70-100 nm in thickness were cut using glass knives on a Reichert Ultracut S ultramicrotome (Vienna, Austria), collected on 400 mesh copper grids (Electron Microscopy Sciences), and stained with $2 \%$ uranyl acetate and lead citrate. The morphology of the isolated mitochondria was studied using a JEOL-100 CX electron microscope (JEOL USA Inc., Peabody, MA, USA) at $80 \mathrm{Kv}$.

\section{Densitometry and statistical analysis}

The relative intensities of the protein bands detected by Western blot were analyzed by densitometry using a BioRad model GS-700 imaging densitometer. The per cent changes in protein concentration were calculated based on the corresponding controls. Statistical analysis was performed using InStat version 2.1 for the ANOVA and Bonferroni's multiple comparison tests. Results are expressed as mean values \pm 1 standard error of the mean (S.E.M.).

\section{Acknowledgments}

The authors thank all members of the laboratory for their comments and encouragement during the course of this work. This work was supported in part by a grant from the Minnesota Medical Foundation to CJ Steer, and by Postdoctoral Fellowhip PRAXIS XXI/BPD/11849/97 and grant PRAXIS/C/SAU/14311/1998 from Fundação para a Ciência e a Technologia, Lisbon, Portugal to CMP Rodrigues.

\section{References}

1. Colombo C, Setchell KDR, Podda M, Crosignani A, Roda A, Curcio L, Ronchi M and Giunta A (1990) Effects of ursodeoxycholic acid therapy for liver disease associated with cystic fibrosis. J. Pediatr. 117: 482489

2. Podda M, Ghezzi C, Battezzati PM, Crosignani A, Zuin M and Roda A (1990) Effects of ursodeoxycholic acid and taurine on serum liver enzymes and bile acids in chronic hepatitis. Gastroenterology 98: 1044-1050

3. Beuers U, Spengler U, Kruis W, Aydemir Ü, Wiebecke B, Heldwein W, Weinzierl M, Pape GR, Sauerbruch T and Paumgartner G (1992) Ursodeoxycholic acid for treatment of primary sclerosing cholangitis: a placebo-controlled trial. Hepatology 16: 707-714

4. Palma J, Reyes H, Ribalta J, Iglesias J, Gonzalez MC, Hernandez I, Alvarez C, Molina C and Danitz AM (1992) Effect of ursodeoxycholic acid in patients with intrahepatic cholestasis of pregnancy. Hepatology 15: 1043-1047

5. Poupon RE, Poupon R, Balkau B and the UDCA-PBC Study Group (1994) Ursodiol for the long-term treatment of primary biliary cirrhosis. N. Engl. J. Med. 330: $1342-1347$

6. Beuers U, Boyer JL and Paumgartner G (1998) Ursodeoxycholic acid in cholestasis: potential mechanisms of action and therapeutic applications. Hepatology 28: $1449-1453$

7. Spivey JR, Bronk SF and Gores GJ (1993) Glycochenodeoxycholate-induced lethal hepatocellular injury in rat hepatocytes. Role of ATP depletion and cytosolic free calcium. J. Clin. Invest. 92: 17-24

8. Patel T, Bronk SF and Gores GJ (1994) Increases of intracellular magnesium promote glycodeoxycholate-induced apoptosis in rat hepatocytes. J. Clin. Invest. 94: 2183-2192 
9. Jones BA, Rao Y-P, Stravitz RT and Gores GJ (1997) Bile salt-induced apoptosis of hepatocytes involves activation of protein kinase C. Am. J. Physiol. 272 G1109-G1115

10. Rodrigues CMP, Fan G, Ma X, Kren BT and Steer CJ (1998) A novel role for ursodeoxycholic acid in inhibiting apoptosis by modulating mitochondrial membrane perturbation. J. Clin. Invest. 101: 2790-2799

11. Botla R, Spivey JR, Aguilar H, Bronk SF and Gores GJ (1995) Ursodeoxycholate (UDCA) inhibits the mitochondrial membrane permeability transition induced by glycochenodeoxycholate: a mechanism of UDCA cytoprotection. J. Pharmacol. Exp. Ther. 272: $930-938$

12. Lieser MJ, Park J, Natori S, Jones BA, Bronk SF and Gores GJ (1998) Cholestasis confers resistance to the rat liver mitochondrial permeability transition. Gastroenterology 115: 693-701

13. Rodrigues CMP, Fan G, Wong PY, Kren BT and Steer CJ (1998) Ursodeoxycholic acid may inhibit deoxycholic acid-induced apoptosis by modulating mitochondrial transmembrane potential and reactive oxygen species production. Mol. Med. 4: 165-178

14. Newmeyer DD, Farschon DM and Reed JC (1994) Cell-free apoptosis in Xenopus egg extracts: inhibition by Bcl-2 and requirement for an organelle fraction enriched in mitochondria. Cell 79: 353-364

15. Liu X, Kim CN, Yang J, Jemmerson R and Wang X (1996) Induction of apoptotic program in cell-free extracts: requirement for dATP and cytochrome c. Cell 86 : $147-157$

16. Kim CN, Wang X, Huang Y, Ibrado AM, Liu L, Fang G and Bhalla K (1997) Overexpression of $\mathrm{Bcl}-\mathrm{x}_{\mathrm{L}}$ inhibits Ara-C-induced mitochondrial loss of cytochrome $c$ and other perturbations that activate the molecular cascade of apoptosis. Cancer Res. 57: 3115-3120

17. Kluck RM, Bossy-Wetzel E, Green DR and Newmeyer DD (1997) The release of cytochrome $\mathrm{c}$ from mitochondria: a primary site for $\mathrm{Bcl}-2$ regulation of apoptosis. Science 275: $1132-1136$

18. Yang J, Liu X, Bhalla K, Kim CN, Ibrado AM, Cai J, Peng T-I, Jones DP and Wang $X$ (1997) Prevention of apoptosis by Bcl-2: release of cytochrome c from mitochondria blocked. Science 275: 1129-1132

19. Neame SJ, Rubin LL andPhilpottKL (1998) Blocking cytochrome cactivity within intact neurons inhibits apoptosis. J. Cell Biol. 142: 1583-1593

20. Zamzami N, Marchetti P, Castedo M, Decaudin D, Macho A, Hirsch T, Susin SA, Petit PX, Mignotte B and Kroemer G (1995) Sequential reduction of mitochondrial transmembrane potential and generation of reactive oxyen species in early programmed cell death. J. Exp. Med. 182: 367-377

21. Zamzami N, Susin SA, Marchetti P, Hirsch T, Gómez-Monterrey I, Castedo M and Kroemer G (1996) Mitochondrial control of nuclear apoptosis. J. Exp. Med. 183: $1533-1544$

22. Marchetti P, Castedo M, Susin SA, Zamzami N, Hirsch T, Macho A, Haeffner A Hirsch F, Geuskens M and Kroemer G (1996) Mitochondrial permeability transition is a central coordinating event of apoptosis. J. Exp. Med. 184: 11551160

23. Petit PX, Susin S-A, Zamzami N, Mignotte B and Kroemer (1996) Mitochondria and programmed cell death: back to the future. FEBS Lett. 396: 7-13.

24. Kroemer G (1997) Mitochondrial implication in apoptosis. Towards an endosymbiont hypothesis of apoptosis evolution. Cell Death Differ. 4: 443-456

25. Kroemer G (1997) The proto-oncogene $\mathrm{Bcl}-2$ and its role in regulating apoptosis. Nat. Med. 3: 614-620

26. Zamzami N, Marchetti P, Castedo M, Hirsch T, Susin SA, Masse B and Kroeme $G$ (1996) Inhibitors of permeability transition interfere with the disruption of the mitochondrial transmembrane potential during apoptosis. FEBS Lett. 384: 53 57

27. Shimizu S, Eguchi Y, Kamiike W, Matsuda H and Tsujimoto $Y$ (1996) Bcl-2 expression prevents activation of the ICE protease cascade. Oncogene 12 2251-2257

28. Shimizu S, Eguchi Y, Kamiike W, Waguri S, Uchiyama $Y$, Matsuda H and Tsujimoto $Y$ (1996) Bcl-2 blocks loss of mitochondrial membrane potential while ICE inhibitors act at a different step during inhibition of death induced by respiratory chain inhibitors. Oncogene 13: $21-29$.

29. Matsuyama S, Schendel SL, Xie Z and Reed JC (1998) Cytoprotection by Bcl-2 requires the pore-forming $\alpha 5$ and $\alpha 6$ helices. J. Biol. Chem. 273: 30995-31001

30. Xiang J, Chao DT and Korsmeyer SJ (1996) BAX-induced cell death may not require interleukin $1 \beta$-converting enzyme-like proteases. Proc. Natl. Acad. Sci. USA 93: $14559-14563$
31. Pastorino JG, Chen S-T, Tafani M, Snyder JW and Farber JL (1998) The overexpression of Bax produces cell death upon induction of the mitochondrial permeability transition. J. Biol. Chem. 273: 7770-7775

32. Narita M, Shimizu S, Ito T, Chittenden T, Lutz RJ, Matsuda H and Tsujimoto $Y$ (1998) Bax interacts with the permeability transition pore to induce permeability transition and cytochrome $c$ release in isolated mitochondria. Proc. Natl. Acad. Sci. USA 95: 14681 - 14686

33. Marzo I, Brenner C, Zamzami N, Jürgensmeier JM, Susin SA, Vieira HLA, Prévost M-C, Xie Z, Matsuyama S, Reed JC and Kroemer G (1998) Bax and adenine nucleotide translocator cooperate in the mitochondrial control of apoptosis.Science 281: 2027-2031

34. Vander Heiden MG, Chandel NS, Williamson EK, Schumacker PT and Thompson CB (1997) Bcl- $x_{L}$ regulates the membrane potential and volume homeostasis of mitochondria. Cell 91: $627-637$

35. Bossy-WetzelE, NewmeyerDD and Green DR (1998) Mitochondrial cytochrome $c$ release in apoptosis occurs upstream of DEVD-specific caspase activation and independently of mitochondrial transmembrane depolarization. EMBO J 17 $37-49$

36. Susin SA, Zamzami N, Castedo M, Daugas E, Wang H-G, Geley S, Fassy F, Reed JC and Kroemer G (1997) The central executioner of apoptosis: multiple connections between protease activation and mitochondria in Fas/APO-1/ CD95- and ceramide-induced apoptosis. J. Exp. Med. 186: 25-37

37. Marzo I, Brenner C, Zamzami N, Susin SA, Beutner G, Brdiczka D, Remy R, Xie Z-H, Reed JC and Kroemer G (1998) The permeability transition pore complex: a target for apoptosis regulation by caspases and Bcl-2-related proteins. J. Exp. Med. 187: 1261 - 1271

38. Eskes R, Antonsson B, Osen-Sand A, Montessuit S, Richter C, Sadoul R, Mazze G, Nichols A and Martinou J-C (1998) Bax-induced cytochrome C release from mitochondria is independent of the permeability transition pore but highly dependent on $\mathrm{Mg}^{2+}$ ions. J. Cell Biol. 143: 217-224

39. JürgensmeierJM, XieZ, Deveraux Q, Ellerby L, Bredesen D and Reed JC (1998) Bax directly induces release of cytochrome $c$ from isolated mitochondria. Proc. Natl. Acad. Sci. USA 95: 4997-5002

40. Okuno S-i, Shimizu S, Ito T, Nomura M, Hamada E, Tsujimoto $Y$ and Matsuda $H$ (1998) Bcl-2 prevents caspase-independent cell death. J. Biol. Chem. 273 $34272-34277$

41. Vayssière J-L,PetitPX, Risler Y and Mignotte B(1994)Commitment to apoptosis is associated with changes in mitochondrial biogenesis and activity in cell lines conditionally immortalized with simian virus 40 . Proc. Natl. Acad. Sci. USA 91 $11752-11756$

42. Krippner A, Matsuno-Yagi A, Gottlieb RA and Babior BM (1996) Loss of function of cytochrome $c$ in Jurkat cells undergoing Fas-mediated apoptosis. J. Biol. Chem. 271: $21629-21636$

43. Susin SA, Zamzami N, Castedo M, Hirsch T, Marchetti P, Macho A, Daugas E, Geuskens M and Kroemer G (1996) Bcl-2 inhibits the mitochondrial release of an apoptogenic protease. J. Exp. Med. 184: 1331-1341

44. Li P, Nijhawan D, Budihardjo I, Srinivasula SM, Ahmed M, Alnemri ES and Wang X (1997) Cytochrome $c$ and dATP-dependent formation of Apaf-1/caspase-9 complex initiates an apoptotic protease cascade. Cell 91: $479-489$

45. Zou H, Henzel WJ, Liu X, Lutschg A and Wang X (1997) Apaf-1, a human protein homologous to $\mathrm{C}$. elegans CED-4, participates in cytochrome c-dependent activation of caspase-3. Cell 90: 405-413

46. Jones B, Roberts PJ, Faubion WA, Kominami E and Gores GJ (1998) Cystatin A expression reduces bile salt-induced apoptosis in a rat hepatoma cell line. Am. J. Physiol. 275: G723-G730

47. Bradham CA, Qian T, Streetz K, Trautwein C, Brenner DA and Lemasters JJ (1998) The mitochondrial permeability transition is required for tumor necrosis factor alpha-mediated apoptosis and cytochrome $c$ release. Mol. Cell. Biol. 18 6353-6364

48. Scaffidi C, Fulda S, Srinivasan A, Fiesen C, Li F, Tomaselli KJ, Debatin K-M, Krammer PH and Peter ME (1998) Two CD95 (APO-1/Fas) signaling pathways. EMBO J. 17: 1675-1687

49. Manon S, Chaudhuri B and Guérin M (1997) Release of cytochrome c and decrease of cytochrome coxidase in Bax-expressing yeast cells, and prevention of these effects by coexpression of Bcl-X. $\mathrm{L}_{\mathrm{L}}$. FEBS Lett. 415: 29-32

50. McCarthy NJ, Whyte MKB, Gilbert CS and Evan GI (1997) Inhibition of Ced-3/ ICE-related proteases does not prevent cell death induced by oncogenes, DNA damage, or the Bcl-2 homologue Bak. J. Cell Biol. 136: 215-227 
51. Rossé T, Olivier R, Monney L, Rager M, Conus S, Fellay I, Jansen B and Borner C (1998) Bcl-2 prolongs cell survival after Bax-induced release of cytochrome $c$. Nature 391: 496-499

52. Han J, Sabbatini P, Perez D, Rao L, Modha D and White E (1996) The E1B 19K protein blocks apoptosis by interacting with and inhibiting p53-inducible and death-promoting Bax protein. Genes Dev. 10: 461-477

53. Zha H, Fisk HA, Yaffe MP, Mahajan N, Herman B and Reed JC (1996) Structurefunction comparisons of the proapoptotic protein Bax in yeast and mammalian cells. Mol. Cell. Biol. 16: 6494-6508

54. Hsu Y-T, Wolter KG and Youle RJ (1997) Cytosol-to-membrane redistribution of Bax and Bcl-X $X_{L}$ during apoptosis. Proc. Natl. Acad. Sci. USA 94: 3668-3672

55. Goping IS, Gross A, Lavoie JN, Nguyen M, Jemmerson R, Roth K, Korsmeyer SJ and Shore GC (1998) Regulated targeting of BAX to mitochondria. J. Cell Biol. 143: $207-215$

56. Gross A, Jockel J, Wei MC and Korsmeyer SJ (1998) Enforced dimerization of $\mathrm{BAX}$ results in its translocation, mitochondrial dysfunction and apoptosis. EMBO J. 17: $3878-3885$

57. Wolter KG, Hsu Y-T, Smith CL, Nechushtan A, Xi X-G and Youle RJ (1997) Movement of Bax from the cytosol to mitochondria during apoptosis. J. Cell Biol. 139: $1281-1292$

58. Antonsson B, Conti F, Ciavatta AM, Montessuit S, Lewis S, Martinou I, Bernasconi L, Bernard A, Mermod J-J, Mazzei G, Maundrell K, Gambale F, Sadoul R and Matinou J-C (1997) Inhibition of Bax channel-forming activity by Bcl-2. Science 277: $370-372$

59. Schlesinger PH, Gross A, Yin X-M, Yamamoto K, Saito M, Waksman G and Korsmeyer SJ (1997) Comparison of the ion channel characteristics of proapoptotic BAX and antiapoptotic BCL-2. Proc. Natl. Acad. Sci. USA 94: $11357-11362$

60. Reed JC (1997) Cytochrome c: can't live with it-can't live without it. Cell 91: $559-562$
61. Finucane DM, Bossy-Wetzel E, Waterhouse NJ, Cotter TG and Green DR (1999) Bax-induced caspase activation and apoptosis via cytochrome $c$ release from mitochondria is inhibitable by Bcl-xL. J. Biol.Chem. 274: 2225-2233

62. Hsu Y-T and Youle RJ (1997) Nonionic detergents induce dimerization among members of the Bcl-2 family. J. Biol. Chem. 272: 13829-13834

63. Hsu Y-T and Youle RJ (1998) Bax in murine thymus is a soluble monomeric protein that displays differential detergent-induced conformations. J. Biol. Chem. 273: $10777-10783$

64. Desagher S, Osen-Sand A, Nichols A, Eskes R, Montessuit S, Lauper S, Maundrell K, Antonsson B and Martinou J-C (1999) Bid-induced conformational change of Bax is responsible for mitochondrial cytochrome $\mathrm{C}$ release during apoptosis. J. Cell Biol. 144: 891-901

65. Mariash CN, Seelig S, Schwartz HL and Oppenheimer JH (1986) Rapid synergistic interaction between thyroid hormone and carbohydrate on $\mathrm{mRNA}_{\mathrm{S} 14}$ induction. J. Biol. Chem. 261: 9583-9586

66. Oberhammer FA, Pavelka M, Sharma S, Tiefenbacher R, Purchio AF, Bursch W and Schulte-Hermann R (1992) Induction of apoptosis in cultured hepatocytes and in regressing liver by transforming growth factor $\beta 1$. Proc. Natl. Acad. Sci. USA 89: 5408-5412

67. Walajtys-Rhode E, Zapatero J, Moehren G and Hoek JB (1992) The role of the matrix calcium level in the enhancement of mitochondrial pyruvate carboxylation by glucagon pretreatment. J. Biol. Chem. 267: 370-379

68. Sokol RJ, Devereaux M, Mierau GW, Hambidge KM and Shikes RH (1990) Oxidant injury to hepatic mitochondrial lipids in rats with dietary copper overload. Modification by vitamin E deficiency. Gastroenterology 99: 1061-1071

69. Pastorino JG, Synder JW, Serroni A, Hoek JB and Farber JL (1993) Cyclosporin and carnitine prevent the anoxic death of cultured hepatocytes by inhibiting the mitochondrial permeability transition. J. Biol. Chem. 268: 13791-13798 